\title{
STUDIES ON GENETIC VARIABILITY AND TRAIT RELATIONSHIP IN CASTOR (RICINUS COMMUNIS L.)
}

\author{
Kasim Alhassan ALHAJI ${ }^{1}$, Ann OLISEH ${ }^{2}$, Bolaji Zuluqurineen SALIHU ${ }^{2 *}$, \\ Maryam Alfa KABARAINI ${ }^{2}$
}

${ }^{1}$ Niger State College of Agriculture, P.M.B. 109, Mokwa - Nigeria

${ }^{2}$ National Cereals Research Institute, Castor Research Programme, P.M.B. 8, Badeggi - Nigeria

${ }^{*}$ Corresponding author. E-mail: mobolajialabi2007@gmail.com

\begin{abstract}
Castor oil plant (Ricinus communis L.) is one of highly treasured industrial oil crop around the world. In the present study, genetic variability and trait relationships in some castor genotypes were examined to generate information for castor breeding purposes in Nigeria. Ten castor genotypes were evaluated in a Randomized Complete Block Design with three replications at the Research Farm of Niger State College of Agriculture, Mokwa, Nigeria. The analysis of variance results showed significant differences among the germplasm for all the traits studied, except leaf petiole length. The seed yield $(\mathrm{kg} / \mathrm{ha})$ ranged between $411.11 \mathrm{~kg} / \mathrm{ha}$ and $1140.00 \mathrm{~kg} / \mathrm{ha}$ with average of $852.19 \mathrm{~kg} / \mathrm{ha}$. High (> 20\%) genotypic and phenotypic coefficient of variations were observed for days to $50 \%$ flowering, number of branches per plant, number of effective racemes per plant, effective raceme length, number of capsules per raceme and height at maturity. Positive and significant genotypic correlations were found between the seed yield, and number of effective racemes per plant $(0.501 * *)$, effective raceme length $(0.402 * *)$, number of capsules per raceme $(0.361 * *)$ and 100 seed weight $\left(0.560^{* *}\right)$. Positive direct effects on the seed yield were observed for nine out of thirteen traits studied. The cluster analysis grouped the genotypes into two main clusters with 4 and 6 cluster members. Based on these findings, it is showed that there is adequate genetic variability in the castor genotypes evaluated. The findings on the trait relationships revealed the raceme characters as important traits for indirect selection for increase in seed yield of castor.
\end{abstract}

Keywords: castor, correlation, path coefficient, trait relationships, variability.

\section{Introduction}

The castor oil plant (Ricinus communis L.) is non-edible oil crop which is widely acknowledged as an ideal industrial crop for tropical and sub-tropical regions, addressing the need for commercial crop with low input costs and valuable returns [SALIHU \& al. 2014]. Castor is a hardy crop easy to establish on the field, resistance to drought, tolerates different types of soil even marginal soil and yield 350-900 kg oil per/ha [GANA, 2015]. The oil, which is extracted from castor seed, is used in the pharmaceutical, rubber/plastic, lubricants/biodiesel and food industries [MUTLU \& MEIER, 2010]. A food condiment (Ogiri), custom to Southern part of Nigeria, is produced from castor seeds [GANA, 2015]. The residual meal of castor seed, after oil extraction, could be used as supplement feed in preparation of broiler finishing diets and also in sheep rations without any harmful effects [ANI \& OKORIE, 2009].

Castor plant varies greatly in its growth and appearance [WEISS, 2000]. It varies in growth habit, seed size and colour, petiole length, branching pattern, capsule number, spike length, germination, flowering, oil content such that different cultivars often bear little resemblance to one another. Assessment of castor genotypic and phenotypic variability through several methodologies has been detailed by RAO \& al. (2009) and 
ZHANG-XISHUN \& YANG-JIAN (2006). Studies on partitioning of phenotypic variability into hereditary segment and non-hereditary (environment) parts have been proposed long ago [SHIVANNA, 2008]. SERVUGAPERUMAL \& al. (2000), in a study on sixty castor cultivars, reported a high genotypic coefficient of variety for seed yield per plant, racemes per plant and plant height. RAO \& al. (2006) detailed that heritable variability existed for the majority of the yield parameters and the traits are normally inherited in a quantitative manner. High heritability was estimated for earliness, seed weight and plant height by SOLANKI \& JOSHI (2000). High genetic variation coupled with high heritability and expected genetic progress for branches per plant, capsules per raceme, length of raceme and seed per plant was documented by SHIVANNA (2008).

However, despite its economic importance, castor has not attained full commercial production in Nigeria due to little research attention. In the present study, studies on genetic variability and trait relationships in some castor genotypes was carried out, in an effort to generate basic information which could be useful to castor breeding programme in Nigeria.

\section{Material and methods}

The experiment was carried out in year 2018 wet season at the Research Farm of Niger State College of Agriculture, Mokwa, Nigeria. The genetic material used for the study comprised of five local and five exotic germplasm obtained from Castor Research Programme of National Cereals Research Institute (NCRI) Badeggi, Nigeria. Sources and some seed physical properties of the germplasm used are presented in the Table 1 . The ten genotypes were grown in a Randomized Complete Block Design (RCBD) with three replications. Plot size of $3 \mathrm{~m} \mathrm{x} 3 \mathrm{~m}$ with inter and intra rows spacing of $0.75 \mathrm{~cm}$ each was used. Two seeds were planted and latter thinned to one seedling per hole after three weeks after planting. Standard agronomic practices for castor were followed.

Data were taken on five plant samples per plot. Parameters considered include Days to 50\% Seedling Sprouting, Days to 50\% Flowering, Height at Flowering, Stem Girth, Leaf Area Index, Petiole Length, Height at Maturity, Days to Maturity, Number of Branches per Plant, Number of Effective Racemes per Plant, Number of Capsule per Spike, Length of Effective Spike, Seed yield per Hectare and 100 Seeds Weight. The data were subjected to analysis of variance (ANOVA). Multivariate analysis was carried out following the procedure of Statistical Tool for Agricultural Research (STAR 2.0.1). Path Analysis was done according to AKINTUNDE (2012).

Table 1. List and Seed physical characteristics of the Castor Genotypes used for the study

\begin{tabular}{cccccccc}
\hline $\begin{array}{c}\text { Acc. } \\
\text { Number }\end{array}$ & Source & Type & Seed Shape & Seed Colour & Seed Mottle & Caruncle & Seed Size \\
\hline Acc.001 & Brazil & Exotic & Square & Black & Less conspicuous & Conspicuous & Large \\
Acc.005 & Nigeria & Local & Oval & Brown & Less conspicuous & $\begin{array}{c}\text { Less } \\
\text { conspicuous }\end{array}$ & Small \\
Acc.006 & Nigeria & Local & Oval & Brown & Less conspicuous & $\begin{array}{c}\text { Less } \\
\text { conspicuous }\end{array}$ & Small \\
Acc.036 & Brazil & Exotic & Oval & Dark-chocolate & Conspicuous & $\begin{array}{c}\text { Less } \\
\text { conspicuous }\end{array}$ & Small \\
Acc.044 & Nigeria & Local & Square & White & Less conspicuous & Conspicuous & Large \\
Acc.045 & Nigeria & Local & Square & White & Less conspicuous & $\begin{array}{c}\text { Less } \\
\text { conspicuous }\end{array}$ & Large
\end{tabular}


Kasim Alhassan ALHAJI \& al.

\begin{tabular}{cccccccc}
\hline Acc.052 & Turkey & Exotic & Oval & Brown & Less conspicuous & $\begin{array}{c}\text { Less } \\
\text { conspicuous }\end{array}$ & Medium \\
Acc.082 & India & Exotic & Oval & Dark-chocolate & Conspicuous & Less & Medium \\
conspicuous & Medium \\
Acc.083 & India & Exotic & Elongated & Brownish Red & Conspicuous & Conspicuous & Large \\
Acc.033 & Nigeria & Local & Elongated & Brown & Conspicuous & Conspicuous & Medium \\
\hline
\end{tabular}

\section{Results}

The analysis of variance (ANOVA) showed significant differences for all the traits studied, except leaf petiole length, among the germplasm (Table 2). Days to 50\% seedling sprouting ranged from 14 to 20 days with average of 16.23 days (Table 2). A range between 40 and 94 days, and average of 60.23 days were observed for days to $50 \%$ flowering. An average of 5.37, with minimum and maximum values of 2 and 14 respectively, was recorded for number of effective racemes per plant among the entries. Number of capsules per raceme varied from 24 to 68 with average of 43.07 capsules. Days to maturity was found to vary from 87 to 123 days with population mean value of 102.93 days. The seed yield ( $\mathrm{kg} / \mathrm{ha}$ ), among the genotypes evaluated, was observed to range between $411.11 \mathrm{~kg} / \mathrm{ha}$ and $1140.00 \mathrm{~kg} / \mathrm{ha}$ with the average being $852.19 \mathrm{~kg} / \mathrm{ha}$. Estimates (Table 2) for coefficient of variations revealed high (> 20\%) genotypic and phenotypic coefficient of variations for days to $50 \%$ flowering (GCV - $26.78 \%$; PCV - 27.20\%), number of branches per plant (GCV - 50.99\%; PCV - 78.62\%), number of effective racemes per plant (GCV - 47.63\%; PCV - 53.93\%), effective raceme length (GCV - 22.59\%; PCV - 29.00\%), number of capsules per raceme (GCV - 22.30\%; PCV - 27.77\%) and height at maturity (GCV 22.85\%; PCV - 27.43\%). Moderate genotypic coefficient of variation $(10<\mathrm{GCV}>20)$ was observed for height at flowering, leaf petiole length, stem girth and 100 seed weight. High heritability $(\mathrm{H} 2>60 \%)$ coupled with high genetic advance as percentage of mean $(\mathrm{GAM}>20 \%)$ were observed for seven traits out of thirteen traits examined (Table 2).

Table 3 presented genotypic correlation coefficients among all the traits studied. Positive and significant genotypic correlations were found between the seed yield, and height at flowering $(0.309 * *)$, number of branches per plant $(0.419 * *)$, number of effective racemes per plant $(0.501 * *)$, effective raceme length $(0.402 * *)$, number of capsules per raceme $\left(0.361^{* *}\right)$, stem girth $\left(0.408^{* *}\right)$, height at maturity $\left(0.327^{* *}\right)$ and 100 seed weight $(0.560 * *)$. Negative and significant correlations to the seed yield were observed for days to seedling sprouting and leaf petiole length. At a residual effect of $12.10 \%$, positive direct effects on seed yield were recorded for all the traits; except height at flowering, leaf petiole length and height at maturity (Table 4). The highest positive direct effect on the seed yield was observed for number of effect racemes per plant and the highest negative direct effect was recorded for height at maturity. Height at flowering and height at maturity exerted positive indirect effects $(0.423$ and 0.337$)$ on the seed yield through days to maturity and stem girth respectively. Days to seedling sprouting showed positive indirect effect on seed yield through number of effective racemes per plant and number of capsules per racemes. Number of branches per plant had positive indirect effect on seed yield through number of effective racemes per plant and effective raceme length. 
STUDIES ON GENETIC VARIABILITY AND TRAIT RELATIONSHIP IN CASTOR...

Table 2. Genetic parameter estimates for thirteen agronomic traits among ten Castor Genotypes

\begin{tabular}{|c|c|c|c|c|c|c|c|c|c|c|c|c|}
\hline Trait & Min & Max & Mean & S.E & MS & $\mathrm{c}^{2} g$ & $\mathrm{c}^{2} \mathrm{p}$ & $\mathrm{c}_{\mathrm{e}}^{2}$ & GCV & PCV & $H^{2}(\%)$ & GAM (\%) \\
\hline DS & 14.00 & 20.00 & 16.23 & 0.31 & $7.63 * *$ & 2.31 & 3.00 & 0.69 & 9.37 & 10.68 & 77.06 & 16.95 \\
\hline DF & 40.00 & 94.00 & 60.23 & 1.89 & $788.89 * *$ & 260.10 & 268.69 & 8.58 & 26.78 & 27.22 & 96.81 & 54.27 \\
\hline HF & 31.00 & 74.20 & 49.81 & 2.27 & $340.52 * *$ & 93.25 & 154.02 & 60.78 & 19.39 & 24.92 & 60.54 & 31.07 \\
\hline LPL & 6.60 & 21.00 & 13.23 & 0.59 & $18.09 \mathrm{~ns}$ & 3.44 & 11.21 & 7.77 & 14.02 & 25.31 & 30.68 & 16.00 \\
\hline BPP & 2.00 & 8.00 & 3.47 & 0.16 & $2.46 * *$ & 0.56 & 1.34 & 0.77 & 50.99 & 78.62 & 42.06 & 68.11 \\
\hline RPP & 2.00 & 14.00 & 5.37 & 0.23 & $4.18 * *$ & 1.27 & 1.63 & 0.36 & 47.63 & 53.93 & 78.00 & 86.65 \\
\hline ERL & 11.80 & 32.80 & 21.53 & 1.11 & $86.27 * *$ & 23.65 & 38.98 & 15.33 & 22.59 & 29.00 & 60.67 & 36.24 \\
\hline CPS & 24.00 & 68.00 & 43.07 & 2.11 & $327.54 * *$ & 92.25 & 143.04 & 50.80 & 22.30 & 27.77 & 64.49 & 36.89 \\
\hline SG & 4.00 & 8.40 & 5.91 & 0.24 & $3.71 * *$ & 0.98 & 1.76 & 0.79 & 16.73 & 22.46 & 55.45 & 25.66 \\
\hline DM & 87.00 & 123.00 & 102.93 & 1.76 & $293.61 * *$ & 96.70 & 100.22 & 3.53 & 9.55 & 9.73 & 96.48 & 19.33 \\
\hline HM & 46.60 & 164.60 & 89.25 & 4.39 & $1431.48 * *$ & 416.04 & 599.41 & 183.37 & 22.85 & 27.43 & 69.41 & 39.22 \\
\hline SY & 411.11 & 1140.00 & 852.19 & 45.23 & $15932.18 * *$ & 3666.78 & 8598.63 & 4931.85 & 7.11 & 10.88 & 42.64 & 9.56 \\
\hline SW & 17.00 & 32.60 & 25.70 & 0.90 & $75.78^{* *}$ & 24.98 & 25.83 & 0.85 & 19.45 & 19.77 & 96.72 & 39.40 \\
\hline
\end{tabular}

Note: $6^{2} g=$ genotypic variance, $6^{2}{ }_{p}=$ phenotypic variance, $6^{2}{ }_{\mathrm{e}}=$ environmental variance, $\mathrm{GCV}=$ genotypic coefficient variance, $\mathrm{PCV}=$ phenotypic coefficient variance, $\mathrm{H}^{2}=$ broad sense heritability, GA = genetic advance, GAM = genetic advance as percentage of mean; DS - Days to 50\% Seedling Sprouting, DF - Days to 50\% Flowering, HF Height at Flowering, SG - Stem Girth, LPL - Leaf Petiole Length, HM - Height at Maturity, DM - Days to Maturity, BPP - Number of Branches per Plant, RPP - Number of Effective Racemes per Plant, CPS - Number of Capsule per Spike, ESL - Length of Effective Spike, SY - Seed yield per Hectare and SW - 100 Seeds Weight. 
Kasim Alhassan ALHAJI \& al.

Table 3. Genotypic correlation coefficients of thirteen agronomic traits among ten Castor Genotypes

\begin{tabular}{|c|c|c|c|c|c|c|c|c|c|c|c|c|c|}
\hline & DS & DF & HF & LPL & BPP & RPP & ESL & CPS & SG & DM & HM & SW & SY/Ha \\
\hline DS & 1 & 0.129 & $-0.405 * *$ & -0.240 & $-0.520 * *$ & 0.158 & $-0.281 *$ & 0.177 & $-0.437 * *$ & -0.161 & $-0.461 * *$ & $-0.622 * *$ & $-0.509 * *$ \\
\hline DF & & 1 & $0.870^{* *}$ & $0.408^{* *}$ & -0.024 & $-0.044 * *$ & $-0.436^{* *}$ & $-0.392 * *$ & 0.226 & $0.784 * *$ & -0.225 & 0.155 & 0.086 \\
\hline HF & & & 1 & $0.646^{* *}$ & $0.330^{* *}$ & -0.110 & $0.512 * *$ & -0.048 & $0.804 * *$ & $0.494 * *$ & $0.798 * *$ & $0.601 * *$ & $0.309 * *$ \\
\hline LPL & & & & 1 & $-0.349 * *$ & -0.228 & $0.264 *$ & 0.070 & $0.741 * *$ & $0.675^{* *}$ & 0.203 & $0.424 * *$ & $-0.256^{*}$ \\
\hline BPP & & & & & 1 & $0.704 * *$ & 0.054 & $-0.338 * *$ & -0.167 & $0.623 * *$ & $0.374 *$ & -0.131 & $0.419 * *$ \\
\hline RPP & & & & & & 1 & -0.113 & $-0.265^{*}$ & -0.084 & $0.542 * *$ & 0.090 & $-0.272 *$ & $0.501 * *$ \\
\hline ESL & & & & & & & 1 & $0.493 * *$ & $0.432 * *$ & 0.029 & $0.603 * *$ & $0.479 * *$ & $0.402 * *$ \\
\hline CPS & & & & & & & & 1 & 0.111 & 0.102 & $0.270 *$ & -0.138 & $0.361 * *$ \\
\hline DM & & & & & & & & & & 1 & 0.044 & $0.463 * *$ & 0.119 \\
\hline HM & & & & & & & & & & & 1 & $0.546^{* *}$ & $0.327 * *$ \\
\hline SW & & & & & & & & & & & & 1 & $0.560 * *$ \\
\hline
\end{tabular}

Note: DS - Days to 50\% Seedling Sprouting, DF - Days to 50\% Flowering, HF - Height at Flowering, SG - Stem Girth, LPL - Leaf Petiole Length, HM Height at Maturity, DM - Days to Maturity, BPP - Number of Branches per Plant, RPP - Number of Effective Racemes per Plant, CPS - Number of Capsule per Spike, ESL - Length of Effective Spike, SY - Seed yield per Hectare and SW - 100 Seeds Weight.

Table 4. Genotypic path coefficients of thirteen agronomic traits among ten Castor Genotypes

\begin{tabular}{cccccccccccccc}
\hline & DS & DF & HF & LPL & BPP & RPP & ESL & CPS & SG & DM & HM & SW \\
\hline DS & $\mathbf{0 . 1 9 8}$ & 0.025 & 0.180 & -0.047 & -0.503 & 0.031 & -0.057 & 0.037 & -0.086 & -0.032 & -0.091 & 0.223 \\
DF & 0.016 & $\mathbf{0 . 1 2 2}$ & -0.476 & 0.050 & -0.003 & -0.005 & -0.553 & -0.048 & 0.028 & 0.096 & -0.027 & 0.029 \\
HF & 0.000 & 0.001 & $\mathbf{- 0 . 0 4 1}$ & 0.001 & 0.260 & 0.000 & 0.001 & 0.023 & 0.001 & 0.000 & 0.012 & 0.001 \\
LPL & 0.260 & -0.273 & -0.432 & $\mathbf{- 0 . 1 7 8}$ & 0.233 & 0.152 & -0.376 & -0.047 & -0.495 & -0.451 & -0.136 & -0.283 \\
BPP & -0.709 & -0.070 & 0.132 & -0.140 & $\mathbf{0 . 4 0 1}$ & 0.282 & 0.422 & -0.266 & -0.067 & -0.250 & 0.150 & -0.053 \\
RPP & 0.397 & -0.027 & -0.098 & -0.140 & 0.433 & $\mathbf{0 . 6 1 6}$ & 0.470 & -0.363 & -0.052 & -0.334 & 0.055 & -0.167 \\
ESL & -0.367 & -0.445 & 0.288 & 0.148 & 0.350 & -0.074 & $\mathbf{0 . 5 6 2}$ & 0.277 & 0.243 & 0.016 & 0.339 & 0.269 \\
CPS & 0.522 & -0.471 & -0.433 & 0.048 & -0.234 & -0.183 & 0.341 & $\mathbf{0 . 5 9 1}$ & 0.177 & 0.071 & 0.187 & -0.095 \\
SG & -0.255 & 0.132 & 0.269 & 0.433 & -0.097 & -0.049 & 0.252 & 0.065 & $\mathbf{0 . 5 0 4}$ & 0.337 & 0.322 & 0.341 \\
DM & -0.073 & 0.354 & 0.423 & 0.304 & 0.281 & 0.244 & 0.013 & 0.046 & 0.260 & $\mathbf{0 . 4 5 1}$ & 0.130 & 0.209 \\
HM & 0.433 & 0.602 & 0.135 & -0.543 & -0.600 & -0.241 & -0.913 & 0.426 & -0.474 & -0.118 & $\mathbf{- 0 . 6 7 5}$ & -0.461 \\
SW & -0.901 & 0.075 & 0.291 & 0.205 & -0.063 & -0.232 & 0.232 & -0.382 & 0.282 & 0.224 & 0.264 & $\mathbf{0 . 4 8 4}$ \\
\hline
\end{tabular}

Note: DS - Days to 50\% Seedling Sprouting, DF - Days to 50\% Flowering, HF - Height at Flowering, SG - Stem Girth, LPL - Leaf Petiole Length, HM

- Height at Maturity, DM - Days to Maturity, BPP - Number of Branches per Plant, RPP - Number of Effective Racemes per Plant, CPS - Number of

Capsule per Spike, ESL - Length of Effective Spike, SY - Seed yield per Hectare and SW -100 Seeds Weight. Residual effect $=0.121$ 
Table 5. Membership performance summary of 10 Castor Genotypes in two Cluster Groups

\begin{tabular}{|c|c|c|c|}
\hline Variable & Statistics & Cluster I & Cluster II \\
\hline \multirow{3}{*}{ Days to $100 \%$ Sprouting } & Min & 14.00 & 17.00 \\
\hline & $\operatorname{Max}$ & 17.00 & 19.00 \\
\hline & Mean & 15.17 & 17.50 \\
\hline \multirow{3}{*}{ Days to $50 \%$ Flowering } & Min & 49.00 & 45.00 \\
\hline & Max & 94.00 & 68.00 \\
\hline & Mean & 69.83 & 55.00 \\
\hline \multirow{3}{*}{$\begin{array}{l}\text { Height at Flowering } \\
(\mathrm{cm})\end{array}$} & Min & 50.60 & 31.20 \\
\hline & $\operatorname{Max}$ & 74.20 & 55.60 \\
\hline & Mean & 60.97 & 41.30 \\
\hline \multirow{3}{*}{$\begin{array}{l}\text { Leaf Petiole Length } \\
(\mathrm{cm})\end{array}$} & Min & 12.00 & 8.40 \\
\hline & $\operatorname{Max}$ & 17.20 & 15.60 \\
\hline & Mean & 14.67 & 11.15 \\
\hline \multirow{3}{*}{ Branches per Plant } & Min & 3.00 & 3.00 \\
\hline & Max & 6.00 & 7.00 \\
\hline & Mean & 4.53 & 5.75 \\
\hline \multirow{3}{*}{$\begin{array}{l}\text { Effective Racemes per } \\
\text { Plant }\end{array}$} & Min & 4.00 & 4.00 \\
\hline & $\operatorname{Max}$ & 8.00 & 10.00 \\
\hline & Mean & 5.33 & 6.53 \\
\hline \multirow{3}{*}{$\begin{array}{l}\text { Effective Raceme } \\
\text { Length }(\mathrm{cm})\end{array}$} & Min & 14.40 & 12.00 \\
\hline & Max & 32.80 & 21.80 \\
\hline & Mean & 25.67 & 17.30 \\
\hline \multirow{3}{*}{ Capsules per Plant } & Min & 24.00 & 32.00 \\
\hline & Max & 62.00 & 63.00 \\
\hline & Mean & 40.17 & 45.75 \\
\hline \multirow{3}{*}{ Stem Girth $(\mathrm{cm})$} & Min & 6.00 & 4.60 \\
\hline & $\operatorname{Max}$ & 8.40 & 5.60 \\
\hline & Mean & 7.10 & 5.00 \\
\hline \multirow{3}{*}{ Days to Maturity } & Min & 92.00 & 88.00 \\
\hline & $\operatorname{Max}$ & 123.00 & 102.00 \\
\hline & Mean & 107.17 & 95.75 \\
\hline \multirow{3}{*}{ Height at Maturity (cm) } & Min & 85.80 & 46.60 \\
\hline & $\operatorname{Max}$ & 164.60 & 92.60 \\
\hline & Mean & 109.07 & 70.40 \\
\hline \multirow{3}{*}{100 Seed Weight (g) } & Min & 26.00 & 18.00 \\
\hline & $\operatorname{Max}$ & 30.60 & 27.00 \\
\hline & Mean & 28.80 & 20.80 \\
\hline \multirow{3}{*}{ Seed Yield (kg/ha) } & Min & 726.67 & 445.56 \\
\hline & Max & 1140.00 & 1035.56 \\
\hline & Mean & 991.67 & 659.73 \\
\hline Number of Members & & 6 & 4 \\
\hline $\begin{array}{l}\text { Membership } \\
\text { (Genotypes Members) }\end{array}$ & & $\begin{array}{l}\text { Gen1 (Acc.001), Gen3 (Acc.006), } \\
\text { Gen5 (Acc.044) Gen6 (Acc.045), } \\
\text { Gen9 (Acc.083), Gen10 (Acc033) }\end{array}$ & $\begin{array}{c}\text { Gen2 (Acc.005), Gen4 } \\
\text { (Acc.036), Gen7 (Acc.052), } \\
\text { Gen8 (Acc.082) }\end{array}$ \\
\hline
\end{tabular}

The result of cluster analysis delineated the ten genotypes evaluated into two main cluster groups (Figure 1). The cluster I had the higher (6) number of cluster members. The cluster pattern showed random distribution of the genotypes into the two groups irrespective of the sources of the genotypes (Table 5). The local genotypes Acc. 006, Acc.044, Acc.045 and Acc. 033 were clustered together with the exotic ones (Acc. 001, Acc. 082 and Acc.033) in cluster I. In the cluster II, the genotypes were exotic, except Acc. 005. Membership performance mean (Table 5) showed that cluster I comprised of high 
Kasim Alhassan ALHAJI \& al.

yield members with average seed yield $(991.67 \mathrm{~kg} / \mathrm{ha})$ greater than the average population mean $(852.19 \mathrm{~kg} / \mathrm{ha})$. The cluster group II, though had low seed yield $(659.73 \mathrm{~kg} / \mathrm{ha})$, contained genotypes with high number of capsules per plant, low days to maturity and shorter height at maturity.

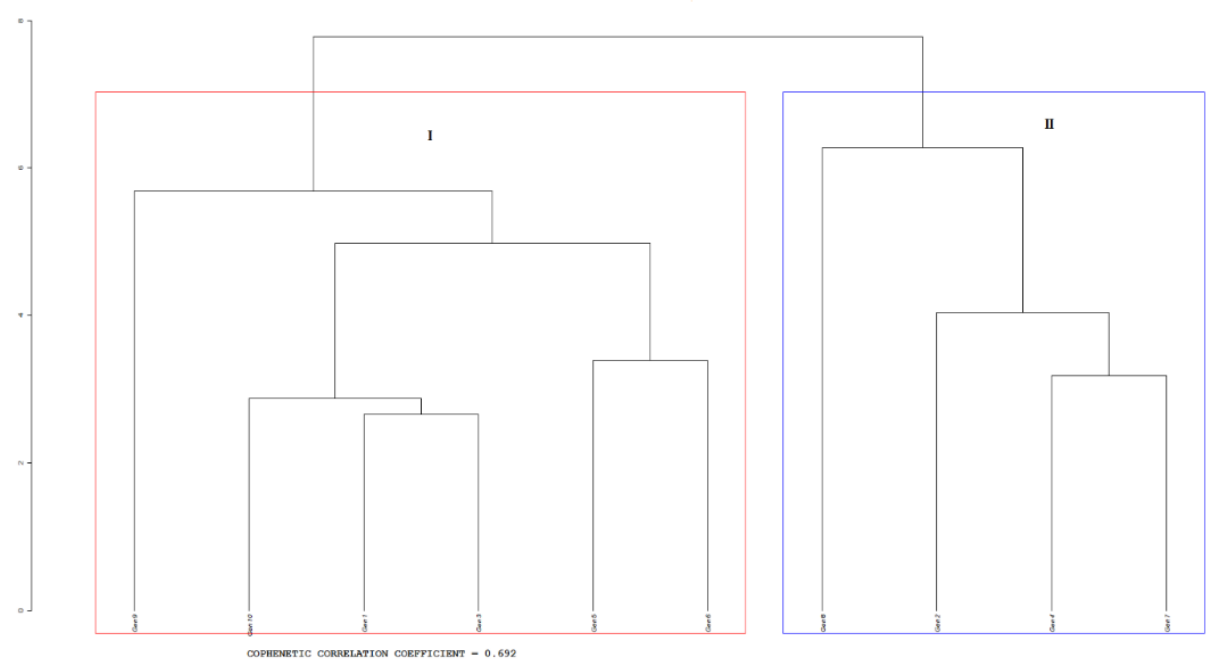

Figure 1. Dendrogram constructed through agglomerative cluster analysis of the ten Castor Genotypes evaluated

\section{Discussion}

The significant differences showed by ANOVA revealed adequate variability for most of the traits among the genotypes evaluated. The magnitude of the variability existed among the genotypes indicated ample scope for selection of most of the traits. SHIVANNA (2008) explained that genotypic coefficient of variation (GCV) and phenotypic coefficient of variation (GCV) could be partitioned as high (> 20\%), moderate (10-20\%) or low (< $10 \%)$. Based on this, moderate to high GCV and PCV were observed for ten out of thirteen characters studied and in all the traits, the magnitude of differences between the GCV and PCV was low for all the traits except for the leaf petiole length branches per plant where it was moderate and high respectively. The low differences is an indication of low influence of environmental factors on the phenotypic expression of genotypes for the traits and as such there is high chance of improving these characters through selection based on the phenotypic data. Earlier researchers [RAO \& al. 2009; ZHANG-XISHUN \& YANG-JIAN, 2006] had reported similar magnitudes of variability in the works on castor. PATEL \& JAIMINI (1988) also reported moderate to high coefficient of variation for most of the traits in castor irrespective of the environment. In a study on the genetic variation of 68 castor lines, LAKSHMAMMA \& al. (2005) reported high genotypic and phenotypic coefficient of variability for capsule weight per plant, plant height, capsule number and leaf area index. GOLAKIA \& al. (2007) observed high PCV for seed yield in his work on castor. This is in contrary to the present findings where low PCV was observed for seed yield. 
The high heritability observed for most of the traits suggested that selection for the traits could be easy and their improvement would be fairly possible using selection breeding. This finding is in accordance with the findings of SHIVANNA (2008) who reported high heritability for all these traits in castor. However, for the best prediction of genetic progress in selection, heritability estimate is said to be along with genetic advance. The high genetic advance as percentage of mean (GAM) observed for most of the traits is an indication that selection at $5 \%$ selection differential could result in high (> 20\%) expected genetic progress (gain) in a selection programme for the traits. Similar results on genetic advance as percentage of mean in castor were reported by LAKSHMAMMA \& al. (2005).

The significant correlations and positive direct effects observed for number of branches per plant, effective number of racemes per plant, effective raceme length, number of capsules per raceme and seed weight indicated true relationship between the seed yield and the mentioned traits and as such direct selection for improvement of these traits would likely be effective as indirect selection for increase in seed yield of castor. The direct effects of effective number of racemes per plant, effective raceme length, number of capsules per raceme and seed weight on seed yield revealed the importance of raceme characters as yield contributors in castor. The results reported here is similar to findings in earlier studies of RAMESH \& VENKATE (2001) who recorded strong correlation between seed yield and plant height to primary raceme, and length of raceme. TORRES \& al. (2015) observed that direct selections of genotypes with tall plant height, wide stem girth, high branching per plant and seed weight are effective to select genotypes with high seed oil. ASWANI \& al. (2003), in his work on castor, reported positive and significant genotypic relationships among seed yield, seed weight, days to flowering, days to maturity and plant height.

The result of the cluster analysis gave insight on possible parental combinations to get useful recombinants. The high yielding cluster group (Cluster I) are the potential parents for increased seed yield. The random distribution of the genotypes into the two cluster groups, irrespective of the geographical sources, revealed no geographic influence on the diversity observed and thus, suggesting other forces such as natural and artificial selection, and genetic drift as contributory factors to the observed genetic divergence among the genotypes. High genetic variability in segregating populations can only be generated by crossing genetically diverse individuals. It has been long theoretically demonstrated that the higher the divergence between the genotypes, the higher will be the heterosis [SHIVANNA, 2008]. Similar absence of correlation between genetic diversity and geographic diversity was also reported by COSTA \& PEREIRA (2006) and ZHANGXISHUN \& YANG-JIAN (2006).

\section{Conclusion}

The results of the study revealed substantial genetic variability in the germplasm evaluated for most of the traits. High genotypic and phenotypic coefficient of variations were observed for days to $50 \%$ flowering, number of branches per plant, number of effective racemes per plant, effective raceme length, number of capsules per raceme and height at maturity. Positive and significant genotypic correlations were found between the seed yield, and height at flowering, number of branches per plant, number of effective racemes per plant, effective raceme length, and number of capsules per raceme, stem girth, height at maturity and 100 seed weight. Positive direct effects on seed yield were observed for all the traits; except height at flowering, leaf petiole length and height at maturity. Out 
Kasim Alhassan ALHAJI \& al.

of all the studied traits, raceme characters are identified as most effective traits for indirect selection for seed yield increase in castor.

\section{Notes on contributors}

Kasim Alhassan ALHAJI is a lecturer/botanist with research interest in crop protection. His research focuses on plant pathology.

Bolaji Zuluqurineen SALIHU is a plant geneticist/breeder with a special interest in plant population improvement. His research focuses on genetic improvement of castor oil plant.

Ann OLISEH is an Agricultural superintendent whose work is focused on crop (castor) husbandry.

Maryam Alfa KABARAINI is a researcher who has research interest in castor disease control and management.

\section{References}

AKINTUNDE A. N. 2012. Path analysis step by step using excel. Journal of Technical Science and Technologies. 1(1): $9-15$.

ANI A. O. \& OKORIE A. U. 2009. Response of broiler finishers to diets containing graded levels of processed castor oil bean (Ricinus communis L.) meal. Journal of Animal Physiology and Animal Nutrition. 93(1): 157-164. https://doi.org/10.1111/j.1439-0396.2007.00796.x

ASWANI K., SANGWAN R. S. \& JATASRA D. S. 2003. Correlations and path analysis in castor (Ricinus communis L.) under dry land conditions. Indian Journal of Dry Land Agricultural Research and Development. 18: 89-91.

COSTA M. N. \& PEREIRA W. E. 2006. Genetic divergence on castor bean associations and cultivars through multivariate analysis. Pesovisa-Agropevaria-Brasileira. 41(1): 1617-1622. http://dx.doi.org/10.1590/ S0100-204X2006001100007

GANA A. K. 2015. Agronomy of Castor. Bida, Nigeria: Khalifa Press: 10-34.

GOLAKIA P. R., KAVANI R. H. \& MONPARA B. A. 2007. Genetic variation and trait relationship in castor. National Journal of Plant Improvement. 9(1): 60-62.

LAKSHMAMMA P., LAKSHMI P., MOHAN Y. C. \& LAVAYANA C. 2005. Genetic variability and character association in castor (Ricinus communis L.). National Journal of Plant Improvement. 7(1): 122-130.

MUTLU H. \& MEIER M. A. R. 2010. Castor oil as a renewable resource for the chemical industry. European Journal of Lipid Science Technology. 112(1): 10-30. https://doi.org/10.1002/ejlt.200900138

PATEL P. S. \& JAIMINI S. N. 1988. Variability in castor. Indian Journal of Agricultural Science. 58(1): $394-396$.

RAO P. V. R., GIRI V. G. \& PACHAURI D. K. 2006. Evaluation of castor (Ricinus communis L.). Research on Crops. 1(1): 699-708.

RAO P. V. R., SHANKAR V. G. \& REDDY A. V. 2009. Variability studies in castor (Ricinus communis L.). Research on Crops. 10(1): 696-698.

RAMESH T. \& VENKATE S. 2001. Path coefficient analysis in castor. Agricultural Science Digest. 21(1): 59-60.

SALIHU B. Z., GANA A. K. \& APUYOR B. O. 2014. Castor Oil Plant (Ricinus communis L.): Botany, Ecology and Uses. International Journal of Science and Research. 3(5): 1333-1341.

SERVUGAPERUMAL S., RANGASWAMY P. \& MUPPIDATHI N. 2000. Genetic variability, correlation and path coefficient analysis in castor. Madras Agricultural Journal. 86(1): 456-459.

SHIVANNA S. 2008. Genetic diversity, combining ability and stability analysis of selected castor lines. PhD Thesis, University of Agricultural Sciences, Bangalore, India.

SOLANKI S. S. \& JOSHI P. 2000. Combining ability analysis over environments of diverse pastille and male parents for seed yield and other trails in castor (Ricinus communis L.). Indian Journal of Genetics and Plant Breeding. 60(1): 201-212.

TORRES F. E., TEODORO P. E., RIBEIRO L. P., CORREA C. C. G., HERNANDES F. B., FERNANDES R. L., GOMES A. C. \& LOPES K. V. 2015. Correlations and path analysis on oil content of castor genotypes. Bioscience Journal. 31(5): 1363-1369.

WEISS E. A. 2000. Oilseed crops. Oxford, England: Blackwell Science: 39-62.

ZHANG-XISHUN Z. \& YANG-JIAN G. 2006. Study on the relationship between genetic distance and heterosis in castor. Scientia Agricultura Sinica. 39(3): 633-640.

\section{How to cite this article:}

ALHAJI K. A., OLISEH A., SALIHU B. Z. \& KABARAINI M. A. 2019. Studies on genetic variability and trait relationship in castor (Ricinus communis L.). J. Plant Develop. 26: 3-11. https://doi.org/10.33628/jpd.2019.26.1.3 